\title{
Role of pulmonary function and FeNO detection in early screening of patients with ACO
}

\author{
JING WANG ${ }^{1}$, WENTING WANG ${ }^{2}$, HUAN LIN $^{2}$, CHENG HUAN $^{2}$, \\ SHUJUAN JIANG ${ }^{1}$, DIANJIE LIN ${ }^{1}$, NAIQING CAO ${ }^{3}$ and HONGSHENG REN ${ }^{2}$ \\ Departments of ${ }^{1}$ Respiration, ${ }^{2}$ Intensive Care Unit and ${ }^{3}$ Allergy, Shandong Provincial Hospital \\ Affiliated to Shandong University, Jinan, Shandong 250021, P.R. China
}

Received July 11, 2019; Accepted February 12, 2020

DOI: $10.3892 /$ etm. 2020.8762

\begin{abstract}
Measurement of fractional exhaled nitric oxide (FeNO) is a quantitative and non-invasive approach to examine airway inflammation, which is a powerful aid in diagnosing chronic disorders of airways like asthma. Diagnostic value of FeNO and relevant indices on pulmonary function in the patients with asthma and chronic obstructive pulmonary disease (COPD) was evaluated. A total of 164 patients [58 asthma, 49 COPD and 57 asthma-COPD overlap (ACO)] were randomly recruited. FeNO, pulmonary ventilation function, and bronchial diastolic function were performed. Eight indicators including FeNO, vital capacity percentage (VC\%), forced vital capacity percentage (FVC\%), forced expiratory volume in one second percentage (FEV1\%), forced expiratory volume in one second to forced vital capacity percentage (FEV1/FVC\%), maximum independent ventilation volume percentage (MVV\%), the increased percentage of FEV1 after bronchial diastolic test, the increased absolute value of FEV1 after bronchial diastolic test were examined. Significant difference in VC\%, FVC\%, FEV1\%, FEV1/FVC\%, MVV\%, the increased absolute value of FEV1 after bronchial diastolic test and $\mathrm{FeNO}$ were significantly different between patients with asthma and patients with COPD $(\mathrm{P}<0.05)$. There were significant differences of VC\%, FVC\%, FEV $1 \%$, FEV1/FVC $\%$, MVV\% and the increased percentage of FEV1 after bronchial diastolic test in cases of patients with asthma compared to ACO patients $(\mathrm{P}<0.05)$. There was no statistical significance on VC\%, FVC\%, FEV1\%, FEV1/FVC\%, MVV\% between COPD patients and ACO patients $(\mathrm{P}>0.05)$. However, more importantly, the increased percentage of FEV1 after bronchial
\end{abstract}

Correspondence to: Dr Hongsheng Ren, Department of Intensive Care Unit, Shandong Provincial Hospital Affiliated to Shandong University, 324 Jingwu Road, Jinan, Shandong 250021, P.R. China E-mail: ren_hongsheng1@163.com

Key words: pulmonary function detection, forced expiratory volume in one second percentage, fractional exhaled nitric oxide, asthma, chronic obstructive pulmonary disease, asthma-COPD overlap diastolic test, the increased absolute value of FEV1 after bronchial diastolic test and the alterations on FeNO were found significantly different in ACO group compared with COPD alone $(\mathrm{P}<0.05)$. We compared the results from pulmonary ventilation function, bronchial diastolic function examination as well as FeNO detection among 3 groups of asthma, COPD and ACO. The examination of pulmonary ventilation function and bronchial diastolic function combined with FeNO detection is helpful in the early screening of ACO.

\section{Introduction}

The two common diseases in the respiratory system are bronchial asthma and chronic obstructive pulmonary disease (COPD) (1). We call it asthma - chronic obstructive pulmonary overlap (asthma - COPD overlap, ACO) if they coexist in the same patient. As early as 1961, Dutch professor Orie suggested that asthma and COPD are different manifestations of the same disease $(1,2)$. The pathogenesis is based on allergic reactions, bronchial hyper-responsiveness and host genetic factors, and is regulated by environmental factors. In 2009, Dr Hunninghake found that the small allele SNPrs2276109 in the MMP12 gene was associated with asthmatic children and patients with smoking COPD (3). The results of Shaya et al (4) also showed an overlap between asthma and COPD. In early 2014, updated version of the COPD Global Prevention Initiative (GOLD) and the May 2014 GINA update were released (5), it was the first time, ACO's predecessor, ACOS, was clearly defined. Updated version of the 2017 Asthma Guide, ACOS is no longer recommended and proposes the term 'asthma - chronic obstructive pulmonary overlap (ACO)'. There are nearly 40 million COPD patients and 30 million asthma patients in China $(6,7)$. Compared with simple asthma and COPD patients, ACO patients will suffer more frequent acute exacerbations and deserve more international attention (8-12). However, some studies have shown that condition of ACO patients tend to inreasingly worsen compared with simple asthma or COPD patients, but ACO patients do not show a higher severity rate than COPD patients (13-15). Our goal was to investigate whether the examination of pulmonary ventilation function and bronchial diastolic function combined with fractional exhaled nitric oxide $(\mathrm{FeNO})$ detection is helpful or not in the early screening of ACO. 


\section{Patients and methods}

Patients. Data were randomly selected from patients with asthma, COPD, and ACO in Department of Respiration, Allergy, Intensive Care Unit (ICU) of the Shandong Provincial Hospital Affiliated to Shandong University (Jinan, China) from January 2016 to September 2019. In this study, 58 cases of asthma patients, 49 patients with COPD, and 57 patients with ACO were screened for pathogenesis history, symptoms, signs, FeNO and routine pulmonary ventilation test indicators and bronchial dilation test. The patients or their relatives signed an informed consent form. This study was approved by the hospital Ethics Committee. This study was registered in Chinese Clinical Trial Registry (clinical trial registry number: ChiCTR-IPC14005596). All enrolled patients met diagnostic criteria and had no other disease affecting pulmonary function testing and FeNO testing.

Methods. A COPD questionnaire was developed based on the epidemiological questionnaire of the World Health Organization's COPD Obesity Lung Disease (BOLD) and our national and environmental factors. The questionnaires were issued to the patients and their families who were admitted to the respiratory department of the unit from January 2016 to September 2019 and their families. The patients were given a lung function test. A bronchodilation test was performed by inhaling salbutamol aerosol if patient's FEV1/FVC was $<70 \%$. The result was confirmed to be COPD with FEV1/FVC $<70 \%$. The criteria of asthema, COPD and ACO was based on international guidelines (16-18). The detection instrument was the German MasterScreen lung function meter; the Shangwana Coulomb Nitric Oxide Detector.

Test indicators. There are 8 specific test indicators. The main indicators of lung function were 7 items: Vital capacity percentage (VC\%), forced vital capacity percentage (FVC\%), forced expiratory volume in one second percentage (FEV1\%), forced expiratory volume in one second to forced vital capacity percentage (FEV1/FVC\%), maximum independent ventilation volume percentage (MVV\%), the increased percentage of FEV1 after bronchial diastolic test, the increased absolute value of FEV1 after bronchial diastolic test. In addition, the 8th test index fractional exhaled nitric oxide (FeNO) of all patients was tested.

Pulmonary function tests. Pulmonary function tests were performed at the Department of Pulmonology at Shandong Provincial Hospital Affiliated to Shandong University according to ATS and ERS standards $(19,20)$. A spirometer (Jaeger Masterscreen, Germany) was used to measure the main indicators of lung function. Fractional exhaled nitric oxide (FeNO) was measured with Shangwana Coulomb Nitric Oxide Detector.

Pulmonary function test subjects were prepared as follows: Before examination, the patients were asked about their medical history, past history and medication situation in detail to judge the indication of pulmonary function test and to exclude contraindications. Accurate measurement of height and weight. Posture: mostly seats, loosen buttons, landing on both feet, sitting upright without backrest, head naturally horizontal or slightly upward. Before the examination, patients watched test demonstration videos and they were given guidance to clamp the nose clip and bite the interface to prevent air leakage and ensure that the chest movement was not restricted.

Notes. VC\% is the percentage of lung volume. FVC\% refers to the percentage of the maximum exhaled volume per unit time, that is, the percentage of exhaled volume from the maximum inspiration to the total lung position, with the greatest effort and the fastest speed, and from the vital capacity to the residual air position. $\mathrm{FVC} \% \approx \mathrm{VC} \%$ in normal people and less than $\mathrm{VC} \%$ in patients with obstruction. FEV1\% is the percentage of exhaled gas volume in one second of forced expiration at the total lung volume position. FEV1\% is the most commonly used parameter and sensitivity index to judge the type and degree of ventilation dysfunction. Its reduction is often earlier than that of $\mathrm{FVC} \%$, indicating the emergence of obstructive ventilation dysfunction. FEV1/FVC\% is the percentage of the ratio of FEV1 to FVC. It is an important index of airflow obstruction. Patients with mild airflow obstruction are given enough time to exhale the gas adequately. Because the decrease of FVC is not obvious, FEV1 has decreased, which leads to the decrease of FEV1/FVC in the early stage. In the case of severe airflow obstruction, FVC decreased significantly due to imperfect exhalation, while FEV1/FVC\% decreased slightly or increased slightly. Therefore, FEV1/FVC\% can reflect the existence of airway obstruction, but can not reflect the degree of airway obstruction. FVC\% and FEV1\% take $80 \%$ of reference value as LIN (lower limit of normal value) (21). The predicted value of $\mathrm{FEV} 1 / \mathrm{FVC} \% \geq 92 \%$ is normal (22). MVV\% refers to the percentage of maximum air volume in and out of the lungs in a unit time. The volume of air obtained by repeating the maximum effort of breathing with the fastest speed and the deepest amplitude in one minute is the product of tidal volume and frequency. It is an important load test that reflects whether the thorax is intact, whether the respiratory tract is unobstructed, whether the respiratory muscles are sound, and whether the elasticity of lung tissue is impaired.

Quality control criteria for FVC examination. No hesitation at the beginning of breathing and rapid peak of expiration. The extrapolated volume is $<5 \% \mathrm{FVC}$ or $<0.151$.

End-of-breath criteria: Patients were unable to continue breathing; respiratory plateau lasted $>1$ sec or expiratory time was $>3$ sec (children $<10$ years old) or $>6$ sec (people $>10$ years old).

Acceptable criteria: Smooth breathing curve; no cough, no interruption; meeting the starting criteria; meeting the end criteria; no glottic closure; no air leakage; no teeth or tongue jammer.

Repeatable criteria: At least 3-8 times; the difference between the best value and the second best value of $\mathrm{FVC}<0.15 \mathrm{l}$; the difference between the best value and the second best value of FEV1<0.15 1. Bronchial drug relaxation test can be given to patients with obstructive ventilation dysfunction. Salbutamol is commonly used. The rate of change of lung function was (FEV1 value after taking medicine - FEV1 value before taking medicine) / FEV1 value before taking medicine, multiplied by $100 \%$. 
Table I. Basic conditions with patients among asthma, COPD and ACO.

\begin{tabular}{lccccccrr}
\hline Disease & $\mathrm{n}$ & $\begin{array}{c}\text { Male/ } \\
\text { female }\end{array}$ & $\begin{array}{c}\text { Average } \\
\text { age }\end{array}$ & $\begin{array}{c}\text { History } \\
\text { of rhinitis }\end{array}$ & Allergies & $\begin{array}{c}\text { Family history } \\
\text { of rhinitis }\end{array}$ & $\begin{array}{c}\text { Family history } \\
\text { of allergies }\end{array}$ & $\begin{array}{r}\text { History of } \\
\text { smoking }\end{array}$ \\
\hline Asthma & 58 & $31: 27$ & $47.57 \pm 14.49$ & 41 & 53 & 17 & 28 & 9 \\
COPD & 49 & $26: 23$ & $62.33 \pm 10.83$ & 15 & 25 & 5 & 6 & 33 \\
ACO & 57 & $30: 27$ & $55.32 \pm 13.07$ & 31 & 52 & 16 & 26 & 15 \\
\hline
\end{tabular}

COPD, chronic obstructive pulmonary disease; ACO, asthma-COPD overlap.

Table II. Comparison of basic conditions with patients between asthma and COPD.

\begin{tabular}{lcccccccc}
\hline Disease & $\mathrm{n}$ & $\begin{array}{c}\text { Male/ } \\
\text { female }\end{array}$ & $\begin{array}{c}\text { Average } \\
\text { age }\end{array}$ & $\begin{array}{c}\text { History } \\
\text { of rhinitis } \\
\text { Yes:no }\end{array}$ & $\begin{array}{c}\text { Allergies } \\
\text { Yes:no }\end{array}$ & $\begin{array}{c}\text { Family history } \\
\text { of rhinitis } \\
\text { Yes:no }\end{array}$ & $\begin{array}{c}\text { Family history } \\
\text { of allergies } \\
\text { Yes:no }\end{array}$ & $\begin{array}{c}\text { History of } \\
\text { smoking } \\
\text { Yes:no }\end{array}$ \\
\hline Asthma & 58 & $31: 27$ & $47.57 \pm 14.49$ & $41: 17$ & $53: 5$ & $17: 41$ & $28: 30$ & $9: 49$ \\
COPD & 49 & $26: 23$ & $62.33 \pm 10.83$ & $15: 34$ & $25: 24$ & $5: 44$ & $6: 43$ & $33: 16$ \\
$\chi^{2}$ & & 0.002 & 4.629 & 17.102 & 21.897 & 5.936 & 15.906 & 29.923 \\
$\mathrm{t}$ & & 6.017 & & & & & $0.001^{\text {a }}$ & $0.001^{\text {a }}$ \\
P-value & & 0.968 & $0.001^{\text {a }}$ & $0.001^{\text {a }}$ & $0.001^{\text {a }}$ & $0.015^{\text {a }}$ & & \\
\hline
\end{tabular}

COPD, chronic obstructive pulmonary disease. ${ }^{\mathrm{a} P}<0.05$.

Diagnostic criteria of diastolic test (23). Positive diastolic test was considered as increased rate of FEV1 $\geq 12 \%$ and the absolute value was $\geq 200 \mathrm{ml}$.

Statistical analysis. The measurement data obtained in this study were expressed as (mean $\pm \mathrm{SD}$ ). The data were analyzed by SPSS 16.0 statistical software package. The t-test was used to compare the measurement data. The $\chi^{2}$ test was used to compare the count data. $\mathrm{P}<0.05$ indicates a statistically significant difference.

\section{Results}

Patients clinical data. Fifty-eight patients with asthma, average age was 47 years, including 31 males, 41 patients with a history of rhinitis, 53 patients with a history of allergies, 17 patients with a history of family rhinitis, 28 patients with a family history of allergies, and 9 smokers. Among the 49 patients with COPD, the average age was 62 years, 26 males, 15 patients with a history of rhinitis, 25 patients with a history of allergies, 5 patients with a family history of rhinitis, 6 patients with a family history of allergies, and 33 smokers. Fifty-seven patients with ACO had an average age of 54 years, 30 males, 31 with a history of rhinitis, 52 with a history of allergies, 16 with a history of family rhinitis, 26 with a family history of allergies, and 15 smokers (Table I).

Basic clinical data. The results of this study found that 58 patients with asthma and 49 patients with COPD had a significant difference on average age, the history of rhinitis, allergies, smoking, family history of rhinitis and family history of allergies $(\mathrm{P}<0.05$; Table II). Comparing 58 patients with asthma to 57 patients with ACO, the basic conditions were not significantly different in sex, the history of rhinitis, allergies, smoking, family history of rhinitis and family history of allergies ( $P>0.05$; Table III). The results of this study found that 49 patients with COPD and 57 patients with ACO had a significant difference in average age, the history of rhinitis, allergies, smoking, family history of rhinitis and family history of allergies $(\mathrm{P}<0.05$; Table IV).

Main lung function indicators between asthma and COPD. The results of this study found that 58 patients with asthma and 49 patients with COPD had significant statistical difference in the main indicators of lung function: $\mathrm{VC} \%, \mathrm{FVC} \%, \mathrm{FEV} 1 \%$, FEV1/FVC\%, MVV\%, the increased absolute value of FEV1 after bronchial diastolic test and FeNO $(\mathrm{P}<0.05)$. There was no significant difference in the increased percentage of FEV1 after bronchial diastolic test with asthma patients compared to COPD patients $(\mathrm{P}>0.05$; Table $\mathrm{V})$.

Main lung function indicators between asthma and ACO. Compared to the lung function indexes of 58 patients with asthma, there was significant statistical differences in $\mathrm{VC} \%$, $\mathrm{FVC} \%, \mathrm{FEV} 1 \%, \mathrm{FEV} 1 / \mathrm{FVC} \%, \mathrm{MVV} \%$, the increased percentage of FEV1 after bronchial diastolic test with 57 ACO patients $(\mathrm{P}<0.05)$. There was no significant difference in the increased absolute value of FEV1 after bronchial diastolic test with asthma patients compared to ACO patients $(\mathrm{P}>0.05)$. FeNO showed no significant difference in the asthma patients group compared to ACO patients group (P>0.05; Table VI). 
Table III. Comparison of basic conditions in patients between asthma and ACO.

\begin{tabular}{|c|c|c|c|c|c|c|c|c|}
\hline Disease & $\mathrm{n}$ & $\begin{array}{c}\text { Male/ } \\
\text { female }\end{array}$ & $\begin{array}{l}\text { Average } \\
\text { age } \\
\text { Yes:no }\end{array}$ & $\begin{array}{l}\text { History } \\
\text { of rhinitis } \\
\text { Yes:no }\end{array}$ & $\begin{array}{c}\text { Allergies } \\
\text { Yes:no }\end{array}$ & $\begin{array}{c}\text { Family history } \\
\text { of rhinitis } \\
\text { Yes:no }\end{array}$ & $\begin{array}{c}\text { Family history } \\
\text { of allergies } \\
\text { Yes:no }\end{array}$ & $\begin{array}{c}\text { History of } \\
\text { smoking } \\
\text { Yes:no }\end{array}$ \\
\hline Asthma & 58 & $31: 27$ & $47.57 \pm 14.49$ & $41: 17$ & $53: 5$ & $17: 41$ & $28: 30$ & $9: 49$ \\
\hline $\mathrm{ACO}$ & 57 & $30: 27$ & $54.32 \pm 13.07$ & $31: 26$ & $52: 5$ & $16: 41$ & $26: 31$ & $15: 42$ \\
\hline $\begin{array}{l}\chi^{2} \\
t\end{array}$ & & 0.008 & $\begin{array}{l}0.768 \\
2.620\end{array}$ & 3.2642 & 0.001 & 0.022 & 0.082 & 2.030 \\
\hline P-value & & 0.930 & $0.010^{\mathrm{a}}$ & 0.071 & 0.977 & 0.883 & 0.775 & 0.154 \\
\hline
\end{tabular}

ACO, asthma-COPD overlap. ${ }^{\mathrm{a}} \mathrm{P}<0.05$.

Table IV. Comparison of basic conditions in patients between COPD and ACO.

\begin{tabular}{|c|c|c|c|c|c|c|c|c|}
\hline Disease & $\mathrm{n}$ & $\begin{array}{c}\text { Male/ } \\
\text { female }\end{array}$ & $\begin{array}{l}\text { Average } \\
\text { age } \\
\text { Yes:no }\end{array}$ & $\begin{array}{l}\text { History } \\
\text { of rhinitis } \\
\text { Yes:no }\end{array}$ & $\begin{array}{c}\text { Allergies } \\
\text { Yes:no }\end{array}$ & $\begin{array}{c}\text { Family history } \\
\text { of rhinitis } \\
\text { Yes:no }\end{array}$ & $\begin{array}{c}\text { Family history } \\
\text { of allergies } \\
\text { Yes:no }\end{array}$ & $\begin{array}{c}\text { History of } \\
\text { smoking } \\
\text { Yes:no }\end{array}$ \\
\hline COPD & 49 & $26: 23$ & $62.33 \pm 10.83$ & $15: 34$ & $25: 24$ & $5: 44$ & $6: 43$ & $33: 16$ \\
\hline $\mathrm{ACO}$ & 57 & $30: 27$ & $54.32 \pm 13.07$ & $31: 26$ & $52: 5$ & $16: 41$ & $26: 31$ & $15: 42$ \\
\hline $\begin{array}{l}\chi^{2} \\
t\end{array}$ & & 0.002 & $\begin{array}{l}1.706 \\
3.401\end{array}$ & 6.063 & 21.434 & 5.294 & 13.921 & 17.903 \\
\hline P-value & & 0.965 & $0.001^{\mathrm{a}}$ & $0.014^{\mathrm{a}}$ & $0.001^{\mathrm{a}}$ & $0.021^{\mathrm{a}}$ & $0.001^{\mathrm{a}}$ & $0.001^{\mathrm{a}}$ \\
\hline
\end{tabular}

COPD, chronic obstructive pulmonary disease; ACO, asthma-COPD overlap. ${ }^{\mathrm{a}} \mathrm{P}<0.05$.

Main lung function indicator between COPD and ACO. The results of this study found that 49 patients with COPD and 57 patients with ACO showed significant statistical significance in increased percentage of FEV1 after bronchial diastolic test, the increased absolute value of FEV1 after bronchial diastolic test and FeNO $(\mathrm{P}<0.05)$. There was no significant difference in $\mathrm{VC} \%, \mathrm{FVC} \%, \mathrm{FEV} 1 \%, \mathrm{FEV} 1 / \mathrm{FVC}$ and $\mathrm{MVV} \%$ between COPD and ACO groups ( $\mathrm{P}>0.05$; Table VII).

\section{Discussion}

Asthma is caused by a variety of cells including eosinophils, mast cells, T lymphocytes, neutrophils, smooth muscle cells, airway epithelial cells as well as airway chronic inflammatory diseases leading to airways (6). Usually, there is a wide variety of reversible airflow limitations. The overall age of onset of asthma is earlier than COPD, usually with a good prognosis $(24,25)$. It is associated with interactions such as allergies, airway inflammation, airway hyper-responsiveness, and neurological factors. COPD is a preventable and treatable disease with airflow limitation. Airflow limitation is not completely reversible and has progressive development. It is associated with abnormal inflammatory reactions caused by smoke or harmful particles (26-29). The pathogenesis is not fully understood, it is generally believed that COPD is characterized by chronic inflammation of the airways, lung parenchyma, and pulmonary blood vessels (6). Macrophages,
T lymphocytes, and neutrophils are increased in different parts of the lung, and some patients also have eosinophilia. It was longer for the patient meeting the diagnostic criteria of COPD, FEV1/FVC $<70 \%$ after the bronchodilation test (17). Although both asthma and COPD are chronic airway inflammatory diseases, the pathogenesis, and clinical manifestations are different. Patients also have significant differences in response to treatment. The airflow limitation of most asthma patients is significantly reversible (30). It is a key feature that is different from COPD. However, some patients with asthma may have more obvious airway remodeling as the disease progresses, resulting in a significant reduction in the reversibility of airflow limitation (31) and it is difficult to distinguish from COPD in clinical practice. Our research showed that there was statistical significance in the $\mathrm{VC} \%, \mathrm{FVC} \%, \mathrm{FEV} 1 \%$, FEV1/FVC\%, MVV\%, the increased absolute value of FEV1 after bronchial diastolic test and FeNO between asthma and COPD patients.

Asthma and COPD occurring in the same patient, was named asthma-chronic obstructive pulmonary overlap (asthma-COPD overlap, ACO) (32). Through our research, we found that this probability is not low. The lung function index of this part of ACO patients began to decrease to a different extent than that of patients with asthma alone, and the reversibility of airway also decreased. Our findings were that there was significant significance on $\mathrm{VC} \%, \mathrm{FVC} \%$, FEV1\%, FEV1/FVC\%, MVV\%, the increased percentage of 

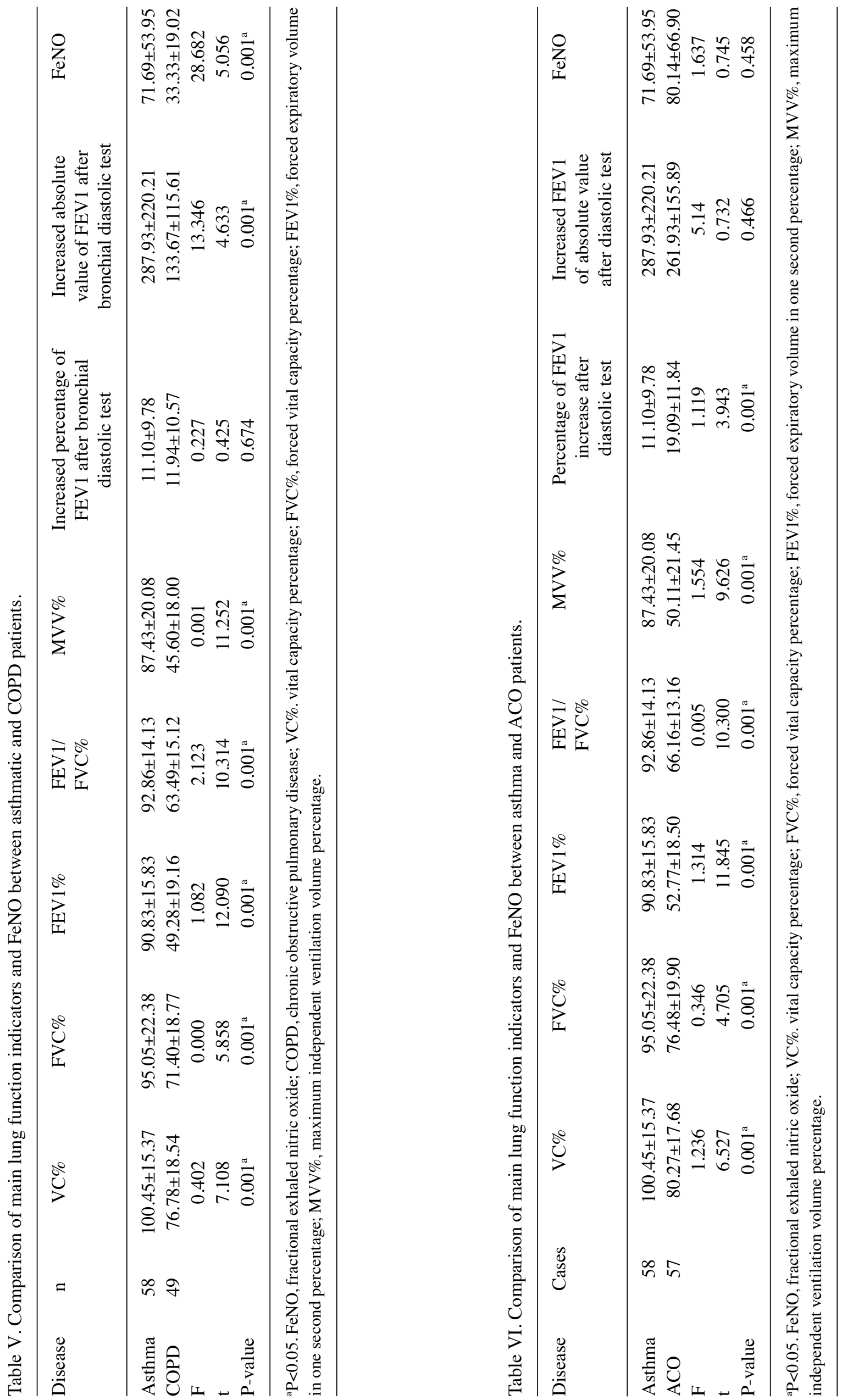
FEV1 after bronchial diastolic test in cases of patients with asthma compared to patients with ACO. Part of the lung function indicators of ACO patients, especially those that reflect the function of the large airway, began to decrease, such as FEV $1 \%$ and FEV1/FVC\%. The mean \pm SD of FEV1\% with asthma patients to ACO patients $(90.83 \pm 15.83$ vs. $52.77 \pm 18.50$, $\mathrm{P}=0.001)$. The mean $\pm \mathrm{SD}$ of FEV1/FVC\% with asthma group to ACO group $(92.86 \pm 14.13$ vs. $66.16 \pm 13.16, \mathrm{P}=0.001)$.

The ratio of forced expiratory volume to forced vital capacity in one second is the most commonly used parameter for judging the type and degree of damage of ventilator dysfunction, and is also a sensitive indicator for judging obstructive ventilator dysfunction. The reduction of FEV1\% is often earlier than the decrease of FVC, which indicates the occurrence of obstructive ventilator dysfunction. This study fully supports the above conclusions. FEV1/FVC\% is an important indicator of airflow obstruction. Patients with mild airflow obstruction given enough time to exhale the gas can fully exhale. In this group of patients, the decline in FVC was not obvious, and FEV1 had decreased, resulting in a decrease in FEV1/FVC in the early stage. In the case of severe airflow obstruction, FVC drops significantly due to imperfect exhalation. The FEV1/FVC decline is not obvious and increases. Therefore, FEV1/FVC can reflect the presence of airway obstruction, but it cannot reflect the extent of airway obstruction (33). Compared with patients with COPD, some patients with ACO have a tendency to reduce the reversibility of the airway. However, the reversible space of the airway is still large. Our research showed that there was no statistical significance in VC\%, FVC\%, FEV1\%, FEV1/FVC\%, MVV\% between $\mathrm{ACO}$ and COPD group. However, importantly, the alterations on FeNO, the increased percentage of FEV1 after bronchial diastolic test, the increased absolute value of FEV1 after bronchial diastolic test were found significantly different in ACO group compared with COPD alone $(\mathrm{P}<0.05)$. There was significant difference in the increased percentage of FEV1 after bronchial diastolic test, with COPD patients compared to ACO patients $(11.94 \pm 10.57$ vs. $19.09 \pm 11.84, \mathrm{P}=0.001)$. There was a significant difference in the increased absolute value of FEV1 after bronchial diastolic test with COPD group compared to ACO group (133.67 \pm 115.61 vs. $261.93 \pm 155.89$, $\mathrm{P}=0.001)$. FeNO in the COPD group compared to ACO group $(33.33 \pm 19.02$ vs. $80.14 \pm 66.90, \mathrm{P}=0.001)$.

This study showed that FeNO was significantly different between asthma group and COPD group $(71.69 \pm 53.95$ vs. $33.33 \pm 19.02, \mathrm{P}=0.001)$. Also, there was a significant difference between ACO and COPD group $(80.14 \pm 66.90$ vs. $33.33 \pm 19.02, \mathrm{P}=0.001)$. So, $\mathrm{FeNO}$ is a sensitive indicator for assisting screening for asthma and ACO patients. The determination of exhaled nitric oxide concentration is one of the most useful and prospective airway inflammation markers. A study has confirmed that FeNO level had a good correlation with eosinophilic airway inflammation (34). It is an indicator that can reflect respiratory inflammation. The determination of FeNO is simple and non-invasive.

Therefore, the examination of pulmonary ventilation function and bronchial diastolic function combined with FeNO detection is helpful in the early screening of ACO and the identification of COPD. It is helpful in finding out the 
untypical clinical symptoms of COPD, to raise awareness of the importance of pulmonary function detection in society, to lay a solid foundation for exploring the early prevention and treatment of ACO and long-term prognosis.

\section{Acknowledgements}

Not applicable.

\section{Funding}

The present study was funded by the Shandong Medical and Health Science and Technology Development Project (grant no. 2014WS0074); Shandong provincial Natural Science Foundation (grant no. ZR2013HM 062); the 2015 Jinan city Bureau of Science \& Technology, Clinical Medicine Science and Technology Innovation Plan (grant no. 201503004); the 2016 Jinan city Bureau of Science \& Technology, Clinical Medicine Science and Technology Innovation Plan (grant no. 201602164); Shandong Provincial Research and Development Plan (grant no. 2016GSF201052).

\section{Availability of data and materials}

The datasets used and/or analyzed during the present study are available from the corresponding author on reasonable request.

\section{Authors' contributions}

JW, WW, HL and HR led the conception and design of this study. JW, CH, SJ, DL and NC were responsible for the data collection and analysis. WW, $\mathrm{HL}$ and $\mathrm{CH}$ were in charge of interpreting the data and drafting the manuscript. JW and HR made revision from critical perspective for important intellectual content. The final version was read and approved by all the authors.

\section{Ethics approval and consent to participate}

The study was approved by the Ethics Committee of Shandong Provincial Hospital Affiliated to Shandong University (Jinan, China; registration no. 2016-008). Signed informed consents were obtained from the patients and/or the guardians.

\section{Patient consent for publication}

Not applicable.

\section{Competing interests}

The authors declare that they have no competing interests.

\section{References}

1. Postma DS and Boezen HM: Rationale for the Dutch hypothesis. Allergy and airway hyperresponsiveness as genetic factors and their interaction with environment in the development of asthma and COPD. Chest 126 (Suppl): S96-S104, discussion S159-S161, 2004.

2. Bleecker ER: Similarities and differences in asthma and COPD. The Dutch hypothesis. Chest 126 (Suppl): S93-S95, discussion S159-S161, 2004.
3. Hunninghake GM, Cho MH, Tesfaigzi Y, Soto-Quiros ME, Avila L, Lasky-Su J, Stidley C, Melén E, Söderhäll C, Hallberg J, et al: MMP12, lung function, and COPD in high-risk populations. N Engl J Med 361: 2599-2608, 2009.

4. Shaya FT, Dongyi D, Akazawa MO, Blanchette CM, Wang J, Mapel DW, Dalal A and Scharf SM: Burden of concomitant asthma and COPD in a Medicaid population. Chest 134: 14-19, 2008.

5. Aaron SD: Global strategy for the diagnosis, management, and prevention of chronic obstructive pulmonary disease (Updated 2014). BMJ 349: 1-11, 2014.

6. Deng DD, Zhou AY, Shuang QC and Chen P: The value of fractionated exhaled nitric oxide in the diagnosis of asthma-chronic obstructive pulmonary disease overlap syndrome. Zhonghua Jie He He Hu Xi Za Zhi 40: 98-101, 2017 (In Chinese).

7. Feng XK, Lin JT, Su N, Liu GL, Chen P, Zhou X, Wan HY, Yin KS and Ma LJ: Investigation and analysis of risk factors of bronchial asthma among people over 14 years old in China. Chin Med J (Engl) 94: 1209-1214, 2014.

8. de Marco R, Pesce G, Marcon A, Accordini S, Antonicelli L, Bugiani M, Casali L, Ferrari M, Nicolini G, Panico MG, et al: The coexistence of asthma and chronic obstructive pulmonary disease (COPD): Prevalence and risk factors in young, middle-aged and elderly people from the general population. PLoS One 8: e62985, 2013.

9. Hardin M, Cho M, McDonald ML, Beaty T, Ramsdell J, Bhatt S, van Beek EJ, Make BJ, Crapo JD, Silverman EK, et al: The clinical and genetic features of COPD-asthma overlap syndrome. Eur Respir J 44: 341-350, 2014

10. Menezes AMB, Montes de Oca M, Pérez-Padilla R, Nadeau G, Wehrmeister FC, Lopez-Varela MV, Muiño A, Jardim JRB, Valdivia G and Tálamo C; PLATINO Team: Increased risk of exacerbation and hospitalization in subjects with an overlap phenotype: COPD-asthma. Chest 145: 297-304, 2014.

11. Milanese M, Di Marco F, Corsico AG, Rolla G, Sposato B, Chieco-Bianchi F, Costantino MT, Crivellaro MA, Guarnieri G and Scichilone N; ELSA Study Group: Asthma control in elderly asthmatics. An Italian observational study. Respir Med 108: 1091-1099, 2014.

12. Alshabanat A, Zafari Z, Albanyan O, Dairi M and FitzGerald JM: Asthma and COPD overlap syndrome (ACOS): A systematic review and meta analysis. PLoS One 10: e0136065, 2015.

13. Bonten TN, Kasteleyn MJ, de Mutsert R, Hiemstra PS, Rosendaal FR, Chavannes NH, Slats AM and Taube C: Defining asthma-COPD overlap syndrome: A population-based study. Eur Respir J 49: 1602008, 2017.

14. Slats A and Taube C: Asthma and chronic obstructive pulmonary disease overlap: Asthmatic chronic obstructive pulmonary disease or chronic obstructive asthma? Ther Adv Respir Dis 10: 57-71, 2016.

15. Cosio BG, Soriano JB, López-Campos JL, Calle-Rubio M, Soler-Cataluna JJ, de-Torres JP, Marín JM, Martínez-Gonzalez C, de Lucas P, Mir I, et al; CHAIN Study: Defining the asthma - COPD overlap syndrome in a COPD cohort. Chest 149: 45-52, 2016.

16. Boulet LP, FitzGerald JM and Reddel HK: The revised 2014 GINA strategy report: opportunities for change. Curr Opin Pulm Med 21: 1-7, 2015.

17. Vogelmeier CF, Criner GJ, Martinez FJ, Anzueto A, Barnes PJ, Bourbeau J, Celli BR, Chen R, Decramer M, Fabbri LM, et al: Global strategy for the diagnosis, management and prevention of chronic obstructive lung disease 2017 report: GOLD executive summary. Respirology 22: 575-601, 2017.

18. Soler-Cataluña JJ, Cosío B, Izquierdo JL, López-Campos JL, Marín JM, Agüero R, Baloira A, Carrizo S, Esteban C, Galdiz JB, et al: Consensus document on the overlap phenocype COPD-Asthma in COPD. Arch Bronconeumol 48: 331-337, 2012 (In English, Spanish).

19. Miller MR, Crapo R, Hankinson J, Brusasco V, Burgos F, Casaburi R, Coates A, Enright P, van der Grinten CP, Gustafsson P, et al; ATS/ERS Task Force: General considerations for lung function testing. Eur Respir J 26: 153-161, 2005.

20. Miller MR, Hankinson J, Brusasco V, Burgos F, Casaburi R, Coates A, Crapo R, Enright P, van der Grinten CP, Gustafsson P, et al; ATS/ERS Task Force: Standardisation of spirometry. Eur Respir J 26: 319-338, 2005.

21. Jiang M, Chen WQ and Zheng JP: Research progress on normal pulmonary ventilation function. Sinochem J Tuberc Respir 36: 973-976, 2013 (In Chinese).

22. Pulmonary Function Professional Group, Society of Respiratory Diseases, Chinese Medical Association. Pulmonary Function Examination (Part 2)-Spirometry Examination. Chin J Tuberc Respir Dis 37: 481-486, 2014 (In Chinese). 
23. Pulmonary Function Professional Group, Society of Respiratory Diseases, Chinese Medical Association. Pulmonary function examination (part IV) - bronchial diastolic test. Chin J Tuberc Respir Dis 37: 655-658, 2014 (In Chinese).

24. Deng TT, Zhou AY, Shuang QC and Cheng P: Value of exhaled nitric oxide in the diagnosis of bronchial asthma - chronic obstructive pulmonary disease overlap syndrome. Chin J Tuberc Respir Dis 40: 98-101, 2017 (In Chinese).

25. Postma DS and Rabe KF: The asthma - COPD overlap syndrome. N Engl J Med 373: 1241-1249, 2015.

26. Mendy A, Salo PM, Cohn RD, Wilkerson J, Zeldin DC and Thorne PS: House dust endotoxin association with chronic bronchitis and emphysema. Environ Health Perspect 126: 037007, 2018.

27. Montes de Oca M and Pérez-Padilla R: Global initiative for chronic obstructive lung disease (GOLD)-2017: The alat perspective. Arch Bronconeumol 53: 87-88, 2017.

28. Barrecheguren M, Esquinas $C$ and Miravitlles $M$ : The asthma-chronic obstructive pulmonary disease overlap syndrome (ACOS): Opportunities and challenges. Curr Opin Pulm Med 21: 74-79, 2015 (In English, Spanish)

29. Sin DD, Miravitlles M, Mannino DM, Soriano JB, Price D, Celli BR, Leung JM, Nakano Y, Park HY, Wark PA, et al: What is asthma-COPD overlap syndrome? Towards a consensus definition from a round table discussion. Eur Respir J 48: 664-673, 2016.

30. Li C, Fang Y and Li ZK: Asthma - COPD overlap syndrome related diseases analysis of 166 cases. Chin J Lung Dis 6: 704-708, 2015 (In Chinese).
31. Kitaguchi Y, Yasuo $M$ and Hanaoka M: Comparison of pulmonary function in patients with COPD, asthma - COPD overlap syndrome, and asthma with airflow limitation. Int J COPD 11: 991-997, 2016 (In Chinese).

32. Gibson PG and Simpson JL: The overlap syndrome of asthma and COPD: What are its features and how important is it? Thorax 64: 728-735, 2009.

33. Zhu L and Shen QJ: Routine pulmonary function parameters and clinical significance in adults. Chin J Tuberc Respir 35: 75-77, 2012 (In Chinese).

34. Koblizek V, Chlumsky J, Zindr V, Neumannova K, Zatloukal J, Zak J, Sedlak V, Kocianova J, Zatloukal J, Hejduk K, et al; Czech Pneumological and Phthisiological Society: Chronic Obstructive Pulmonary Disease: Official diagnosis and treatment guidelines of the Czech Pneumological and Phthisiological Society; a novel phenotypic approach to COPD with patient-oriented care. Biomed Pap Med Fac Univ Palacky Olomouc Czech Repub 157: 189-201, 2013.

This work is licensed under a Creative Commons Attribution-NonCommercial-NoDerivatives 4.0 International (CC BY-NC-ND 4.0) License. 